\title{
The amelioration of nicotine-induced reproductive impairment in male mouse by Sambucus ebulus L. fruit extract
}

\author{
Fahimeh Mohammadghasemi ${ }^{1}$, Korosh Khanaki ${ }^{2}$, Hamid Moravati ${ }^{3}$, Masoumeh Faghani ${ }^{1}$ \\ ${ }^{1}$ Cellular \& Molecular Research Center, School of Medicine, Guilan University of Medical Sciences, Rasht, Iran, ${ }^{2}$ Medical Biotechnology Research \\ Center, School of Paramedicine, Guilan University of Medical Sciences, Rasht, Iran, ${ }^{3}$ Animal Lab, School of Medicine, Guilan University of Medical \\ Sciences, Rasht, Iran
}

\begin{abstract}
Nicotine as a toxic agent in cigarette smoke impairs the reproductive system. Sambucus ebulus extract (SEE) is shown to have some beneficial effects such as antioxidant properties. The aim of this study was to evaluate the effects of SEE on the hormones of the pituitary-gonadal axis, lipid peroxidation index, antioxidant enzymes, spermatogenesis, and epididymal sperm parameters in male mice treated with nicotine. Adult male mice were divided into five groups; A: normal saline, B: $1 \mathrm{mg} / \mathrm{kg}$ nicotine, C: $1 \mathrm{mg} / \mathrm{kg}$ nicotine and $10 \mathrm{mg} / \mathrm{kg}$ SEE, D: $1 \mathrm{mg} / \mathrm{kg}$ nicotine and $50 \mathrm{mg} / \mathrm{kg}$ SEE, D: $1 \mathrm{mg} / \mathrm{kg}$ nicotine and $100 \mathrm{mg} / \mathrm{kg}$ SEE. Treatments lasted for 35 days. The spermicidal activity of SEE was tested in vitro. Sperm count, motility and morphology were assessed for fertility. Serum testosterone, prolactin and luteinizing hormone (LH) were measured, using ELISA. Serum malondialdehyde (MDA), catalase (CAT), and superoxide dismutase (SOD) activity were measured, using colorimetric assays. Spermatogenesis was evaluated by Johnsen's score and morphometry in histological slides. SEE at different doses did not have any spermicidal activity. Sperm parameters were reduced in the nicotine-treated group, compared with controls $(P<0.01)$. Nicotine reduced testosterone and LH levels $(P<0.01)$ and increased prolactin $(P<0.01)$. A hike in MDA and a reduction in SOD activity without change on CAT, were observed in the nicotine group. Nicotine caused hypospermatogenesis. SEE improved most of the above-mentioned parameters, especially in the doses of 50 and 100 $\mathrm{mg} / \mathrm{kg}$. Beneficial effects of SEE in the doses of 50 and $100 \mathrm{mg} / \mathrm{kg}$ on male reproduction impairment, induced by nicotine might be partly attributed to the reduction of oxidative stress and changes in the hormones of the pituitary-gonadal axis.
\end{abstract}

Key words: Nicotine, Sambucus ebulus, Reproduction, Spermatogenesis, Oxidative stress

Received June 24, 2020; Revised September 25, 2020; Accepted January 7, 2021

\section{Introduction}

Nicotine is the most important toxic agent in the cigarette and has a rapid action on the body organs. It has side effects on multiple organs, including respiratory, cardiovascular [1],

Corresponding author:

Masoumeh Faghani (iD

Cellular \& Molecular Research Center, Faculty of Medicine, Guilan University of Medical Sciences, Rasht 41635-3363, Iran

E-mail:mfaghani200o@gmail.com gastrointestinal $[1,2]$, ocular, renal and immunological systems, [1], as well as female [3, 4], and male [5-7] reproductive function.

The most important function of the testis is spermatogenesis and synthesis of androgens. Any changes in endocrine gland function, especially the hypothalamus and pituitary glands resulted in impaired spermatogenesis. Nicotine affects the hypothalamic-pituitary-gonadal axis through its effect on follicle-stimulating hormone (FSH) and luteinizing hormone $(\mathrm{LH})[5,7,8]$, testosterone $[5,7]$, prolactin [7] and estradiol $[4,9]$ secretion. It also alters key steroidogenic 
enzyme expressions $[8,10]$. In testis tissue, due to the continuation of the spermatogenesis process, the proliferation and metabolism of germ cells are high. On the other hand, testicular tissue possesses a high amount of unsaturated fatty acids, therefore, the testicles may be an environment with high production of reactive oxygen species (ROS) [11]. Due to the relative insufficient blood flow in testis, testicles are very susceptible to hypoxia and oxidative stress [12]. It has been shown that cigarette smoke induces acute vascular effects in both the brain and testis [13]. Nicotine impairs the synthesis of nitric oxide (NO), therefore, resulted in erectile dysfunction and penile erection [1]. It has been shown that nicotine increases ROS and cell stresses. Additionally, ROS also have an inhibitory effect on steroidogenic acute regulatory (StAR) protein, leading to disturbed steroidogenesis $[8,14]$. Nicotine increases testicular lipid peroxidation and reduces testicular antioxidant [6]. It has been shown that smoking increases ROS levels. Levels of seminal ROS in smokers increase by $107 \%$. In smokers, the concentration of lead and cadmium is elevated both in blood flow and semen that leads to elevation of ROS. ROS through the induction of apoptosis in testis diminishes male fertility [15]. Nicotine disturbs male gonadal function and sperm parameters both in humans and animals [5, 16-18].

Antioxidant compounds may be useful to ameliorate the toxic effects of nicotine and other toxic agents on male reproduction. Consumption of antioxidants increases the activity of the antioxidant system. The best natural exogenous antioxidants are vitamins and polyphenols. Polyphenolic compounds, especially flavonoids, possess high antioxidant properties; Sambucus ebulus L. extensively grows in the northern part of Iran. Sambucus ebulus L. is known as a source for natural antioxidant and flavonoid compounds [19]. It is used in traditional medicine for inflammatory reactions such as bee and nettle bites, arthritis, and sore-throat [20].

It also has antioxidant, anticancer, antidiabetic, and antidepressant properties [19]. Both roots, fruits and leaves of the Sambucus ebulus have anti-carcinogenic effects in cell lines derived from different tumors [21]. Sambucus ebulus through inhibition of $\alpha$-amylase and $\alpha$-glucosidase have also antidiabetic effects [19]. Sambucus ebulus fruit improves lipid profiles in healthy volunteers[22]. In patients with knee osteoarthritis Sambucus ebulus gel reduces the clinical signs [23]. Sambucus ebulus inhibits tyrosinase enzyme, and therefore it may be used for skin diseases related to melanin hyperpigmentation [19]. In mice, Sambucus ebulus has a pro- tective effect in lung damages induced by gamma irradiation [24].

In this study, we were aimed to study the effect of Sambucus ebulus L. fruit extract on spermatogenesis and epididymal sperm parameters in adult male mice treated with nicotine.

\section{Materials and Methods}

\section{Preparation of extract}

The genus and species of Sambucus ebulus fruit were confirmed by the Pharmacology Department of Guilan University of Medical Sciences (Herbarium number: 301HGUM). The fruits were dried at room temperature and away from direct sunlight and then powdered. The ethanol solvent was used for extraction. After centrifugation, the extracts were concentrated in the rotary vacuum with an evaporator. Then extracts were transferred to an oven and dried completely at $40^{\circ} \mathrm{C}$. To prepare the extract in the required concentrations, $1 \mathrm{~g}$ of the extract powder was dissolved in $10 \mathrm{ml}$ of distilled water. Our working solution was prepared for the required doses.

\section{In vitro spermicidal test of Sambucus ebulus extract}

The spermicidal activity of Sambucus ebulus extracts (SEEs) at different doses of 0, 5, 10, 20, 50, $100 \mathrm{mg}$ was tested in vitro. For this purpose, epididymis was put in a pre-warmed Dulbecco's modified Eagle medium (DMEM) solution at $37^{\circ} \mathrm{C}$ inside the incubator. After 30 minutes and releasing of sperms into the DMEM solution, we added and mixed $100 \mu \mathrm{l}$ sperm solution and $100 \mu \mathrm{l} 0,5,10,20,50$, and $100 \mathrm{mg}$ of SSE in different central dishes, and each mixed solution was pipetted up and down. The percentage of sperm motility was recorded in each solution after $0,30,60$, and 120 minutes of incubation, using light microscopy in at least 200 cells. The test was repeated twice for each concentration. The lowest concentration of SSE, which was killing 100\% sperms immediately ( 0 minutes) after treatment, was considered as an optimal concentration of the spermicidal agents.

For the study of the viability of sperms, we used 1\% Eosin$\mathrm{Y}$ staining. For this purpose, equal volumes $(20 \mu \mathrm{l} / 20 \mu \mathrm{l})$ of Eosin Y and treated sperms with different extract concentrations were mixed well and pipetted. Then a drop $(20 \mu \mathrm{l})$ was mounted on a slide and covered with a cover glass for about 1 minutes, and observed with a light microscope. The unstained sperms (light cells) were considered alive and the 
stained sperms (red cells) were considered as dead cells. The numbers of vital and dead cells were counted in at least 200 cells and averaged and expressed as a percent $[25,26]$.

\section{Animals}

In this study, 30 adult NMRI male mice aged 10-12 weeks and weighing 35-40 g were obtained from the Pasteur Institute, Tehran, Iran, and divided into five groups (6 per group). The animals were maintained under standard lighting conditions (12 hours light-dark cycles) at $25^{\circ} \mathrm{C} \pm 2^{\circ} \mathrm{C}$ with free access to water and food. They were allowed to adapt for at least 1 week in the animal room before they were subjected to treatment. Animals were maintained and handled, according to the protocols approved by the Animal Care and Use Committee of Guilan University of Medical Sciences (Ethical Code: 96090410). Animals were divided randomly into five groups. Group A: Mice received normal saline. Group B: Mice received $1 \mathrm{mg} / \mathrm{kg}$ of nicotine (Sigma-Aldrich GmbH, Steinheim, Germany). Group C: Mice received $1 \mathrm{mg} /$ $\mathrm{kg}$ nicotine, and $10 \mathrm{mg} / \mathrm{kg}$ SEE. Group D: Mice received 1 $\mathrm{mg} / \mathrm{kg}$ nicotine, and $50 \mathrm{mg} / \mathrm{kg}$ SEE. Group D: Mice received $1 \mathrm{mg} / \mathrm{kg}$ nicotine, and $100 \mathrm{mg} / \mathrm{kg} \mathrm{SEE}$. All groups were injected intraperitoneally once daily for 35 days.

The selected dose of nicotine in this study $(1 \mathrm{mg} / \mathrm{kg})$, is equivalent to the human serum levels of nicotine in those who smoke 20 cigarettes per day [6,27].

The selected doses of 10,50 , and $100 \mathrm{mg} / \mathrm{kg}$ SEE were based on our pilot animal study. We tested testicular histology and epididymal sperm parameters at different concentrations of 5, 10, 20,50, and $100 \mathrm{mg} / \mathrm{kg}$ of SEE (4 animals for each concentration). The best results were observed in 50 and $100 \mathrm{mg} / \mathrm{kg}$ of SEE. Therefore, we chose the doses of 10 , 50 , and $100 \mathrm{mg} / \mathrm{kg}$ for our evaluations.

\section{Animal sampling}

On day 36, all animals were killed by cervical dislocation. Then, their blood was taken through the inferior vena cava for hormonal assay and the study of oxidative stress markers. Right and left epididymis removed for the evaluation of sperm parameters. The right testis was used for histopathological evaluations.

\section{Hormonal assay}

After collecting the blood samples, they were centrifuged at 3,000 rpm for 10 minutes. Then, the serum was separated and stored in a refrigerator at $-20^{\circ} \mathrm{C}$. Testosterone, $\mathrm{LH}$, and prolactin hormones were assayed with an ELISA kit (Monobind, Lake Forest, CA, USA). All procedures were performed, using the kit's instructions. The sensitivity for testosterone was $0.0576 \mathrm{ng} / \mathrm{m}$. The sensitivity for $\mathrm{LH}$ and prolactin were $0.010 \mathrm{mIU} / \mathrm{ml}$ and $0.150 \mathrm{ng} / \mathrm{ml}$, respectively.

\section{Sperm parameters}

The caudal part of epididymis was used for the evaluation of sperm parameters. Samples were put in a pre-warmed Ham's F10 (Sigma) solution and incubated at $37^{\circ} \mathrm{C}$ with $5 \%$ $\mathrm{CO}_{2}$ for half an hour. Following pipetting, $10 \mu \mathrm{l}$ of the solution was mounted on a slide, and motility was studied, using a light microscope at $400 \times$ magnification. The motility was divided into rapid and progressive motility and nonmotile sperms. The percent of each grade was recorded in 5 microscopic fields. For measuring the sperm counts, sperm suspension was diluted (1:5) with a formaldehyde solution. A Neubauer slide was used for counting sperm heads in five cells and expressed as per milliliter. For evaluation of sperm morphology, $10 \mu \mathrm{l}$ of the solution was smeared and dried. After fixing in $96 \%$ ethanol and drying, the slides were stained with Hematoxylin \& Eosin (H\&E). Then, using a light microscope with 1,000× magnification, the abnormalities in head and tail were recorded and expressed as abnormal sperms.

\section{Histopathology of testis}

Testicular tissues were fixed in Bouin solution. Following fixation, the samples were dehydrated with graded doses of ethanol, and then cleared with xylene, and finally embedded with paraffin. Sections with a $5 \mu \mathrm{m}$ thickness were prepared with a rotary microtome. Slides were stained with H\&E and observed for quality and quantity of spermatogenesis assessment.

\section{Quality of spermatogenesis}

For quality evaluation of spermatogenesis, Johnsen's score was used. Seminiferous tubule's maturity was scored from 1 to $10[28]$.

\section{Morphometric study}

The numbers of Leydig cells were recorded in the microscopic field with a $400 \times$ magnification. In each animal, 5 fields were recorded. The thickness of the germinal epithelium $(\mathrm{Ge})$ and seminiferous tubule diameters were measured, using a linear scaled grade, which was inserted on the 
eyepiece of the microscope. In each animal, 20 seminiferous tubules at VII and VIII stages with a round section were used $[29,30]$.

\section{Oxidative markers and antioxidant enzymes}

The serum malondialdehyde (MDA) level, as an index of lipid peroxidation was measured, using a kit (Zell bioGMBH, Wurttemberg, Germany), based on the colorimetric method and following the manufacturer's recommendations. The limit of detection (LoD) for MDA was $0.1 \mu \mathrm{M}$. Also, the activity of antioxidant enzymes: catalase (CAT) and superoxide dismutase (SOD), in the serum was determined, using the colorimetric method (Zell bio-GMBH, Wurttemberg, Germany). LoD for CAT and SOD was $0.5 \mathrm{U} / \mathrm{ml}$, and $1 \mathrm{U} / \mathrm{ml}$, respectively.

\section{Statistical analysis}

Values were expressed as mean \pm standard error of the mean. For statistical analysis, the SPSS program and one-way ANOVA were used. Subsequently, to evaluate the difference between groups, Tukey's post-hoc test was used. Findings were considered significant if $P<0.05$.

\section{Results}

\section{In vitro spermicidal activity of Sambucus ebulus extract}

In vitro study of the spermicidal activity of SSE at different concentrations showed no spermicidal activity for SSE at all doses. In control ( $0 \mathrm{mg} \mathrm{SSE}$ ), the motile sperms were observed at all times and the motility was reduced over time. Similarly, the treated sperms with 5, 10, 20, 50, and $100 \mathrm{mg}$
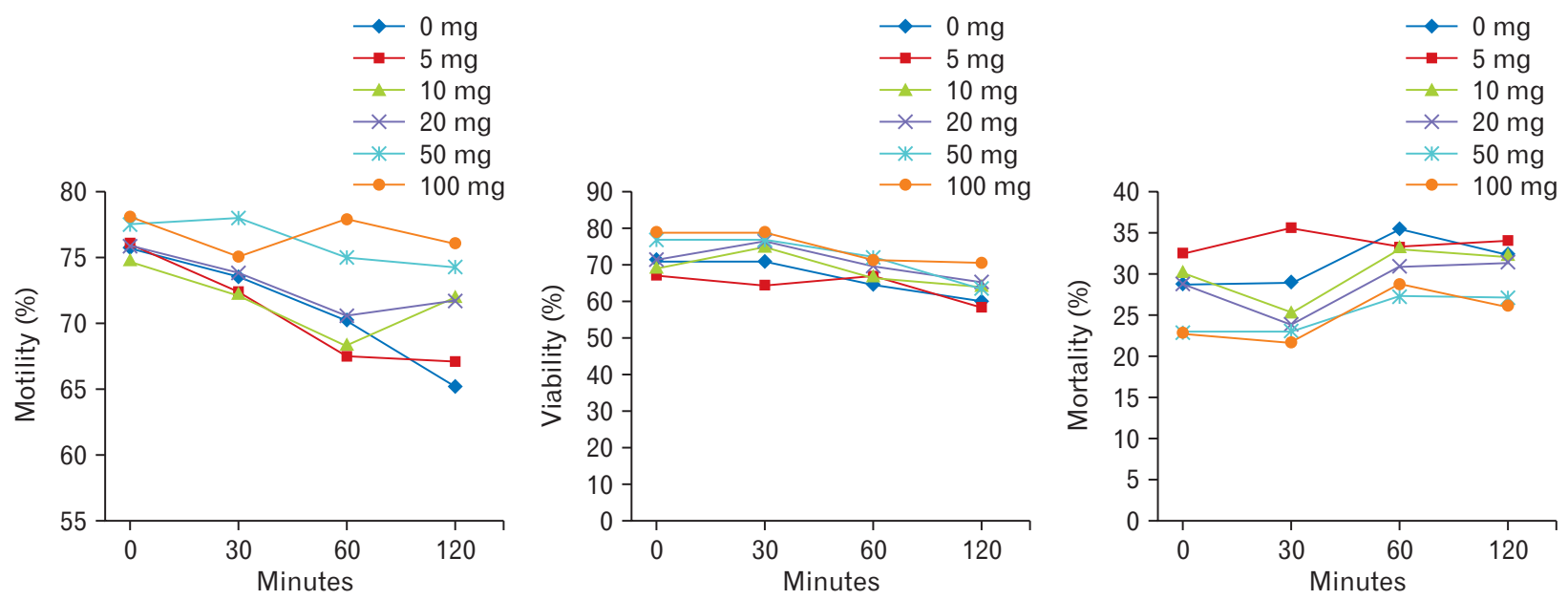

Fig. 1. The sperm viability and motility percentage following treatment with 0, 5, 10, 20, 50 and $100 \mathrm{mg}$ of Sambucus ebulus at different time points.
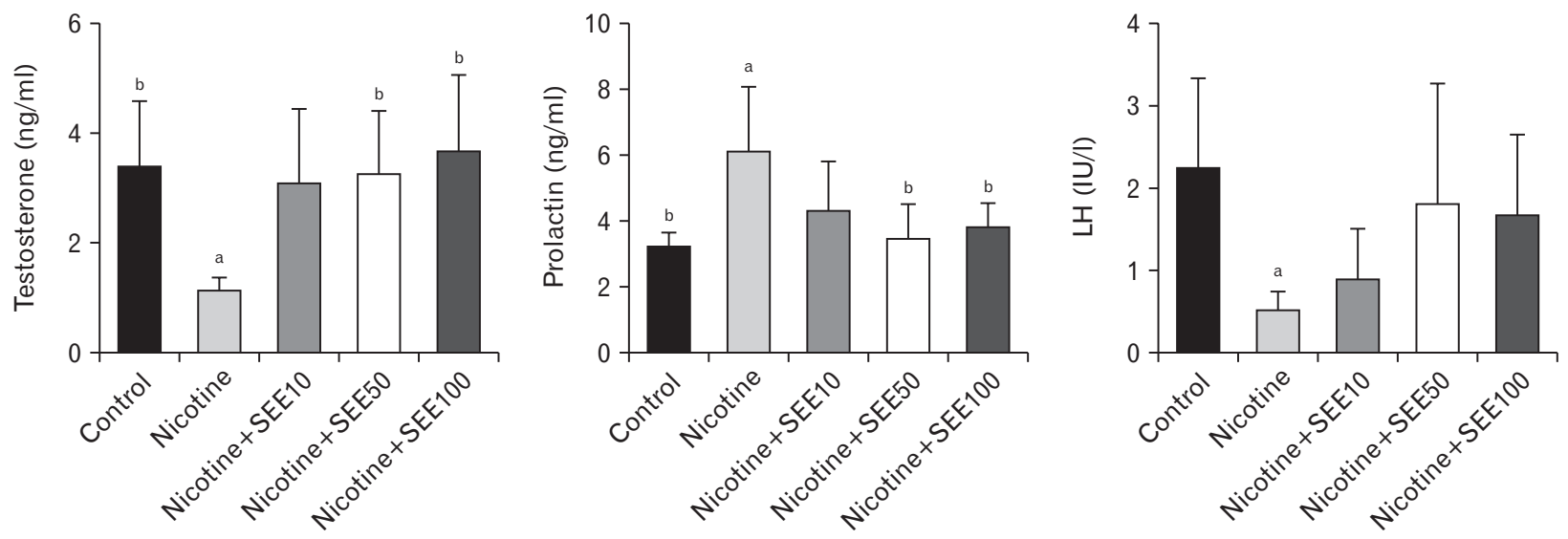

Fig. 2. Hormone profile in different groups treated with nicotine and SEE. ${ }^{a}$ Significant data in comparison with control $P<0.01$. ${ }^{\mathrm{b}}$ Significant data compared with nicotine $P<0.05$. Values are expressed as mean. SEE, Sambucus ebulus extract. 
of SSE had high motility. There were no significant statistical differences in motile sperms between treated sperms and control $(0 \mathrm{mg})$, after 0,30 , and 60 minutes. However, the motile sperms in treated sperms with 50 and $100 \mathrm{mg}$ of SSE were significantly increased in 120 minutes, when compared with control (0 mg SSE) $(P<0.01)$ (Fig. 1).

Using the Eosin-Y staining in control (0 mg SSE), 67.5\% sperm viability was determined after 120 minutes. There were no significant statistical differences in the viability of sperms between all treated sperms and $0 \mathrm{mg} / \mathrm{kg}$ SSE at different time points (Fig. 1). Sperm mortality increased in all treated sperms over time. However, there were no significant statistical differences in the mortality percentage between sperms at different doses of SSE (Fig. 1).

\section{Hormonal results}

The hormonal profile showed that nicotine-induced a significant reduction in testosterone and LH levels $(P<0.01)$, with a significant increase in prolactin $(P<0.01)$ (Fig. 2). Co-treatment with nicotine and $10 \mathrm{mg} / \mathrm{kg}$ of SEE had no significant effect on all hormones. We observed increased testosterone and reduced prolactin without alteration in $\mathrm{LH}$, in co-treatment with nicotine and $50 \mathrm{mg} / \mathrm{kg}$ and $100 \mathrm{mg} / \mathrm{kg}$ of SEE, compared with the nicotine only-treated group (Fig. 2).

\section{In vivo sperm parameters}

Nicotine induced a decrease in sperm count, progressive and total motility (Table 1). It also increased abnormal sperms $(P<0.01)$. SEE in the doses of 50 and $100 \mathrm{mg} / \mathrm{kg}$ caused an increase in sperm count and progressive motility and a decrease in abnormal sperms. There was no significant difference in sperm parameters between $10 \mathrm{mg} / \mathrm{kg}$ of SEE with the nicotine-treated group (Table 1).

\section{Oxidative markers and antioxidant enzymes}

Our findings showed a significant reduction in serum SOD activity in the nicotine group, compared with controls $(P<0.01)$ (Fig. 3). An insignificant increase was observed in the SOD level in SEE-treated groups, in comparison with the nicotine-treated group. There were no significant statistical differences between co-treatment of SEE-nicotine groups in

Table 1. The effect of SEE on epididymal sperm parameters in mice treated with nicotine

\begin{tabular}{lcccc}
\hline \multicolumn{1}{c}{ Groups } & Control & Nicotine & Nicotine+SEE 10 mg/kg & Nicotine+SEE 50 mg/kg Nicotine+SEE 100 mg/kg \\
\hline Sperm count $\left(\times 10^{6} / \mathrm{ml}\right)$ & $38.98 \pm 3.60^{\mathrm{b}}$ & $22.83 \pm 2.31^{\mathrm{a}}$ & $23.17 \pm 2.22^{\mathrm{a}}$ & $31.50 \pm 2.16^{\mathrm{ab}}$ \\
Progressive motility (\%) & $11.00 \pm 0.89^{\mathrm{b}}$ & $3.17 \pm 1.47^{\mathrm{a}}$ & $3.67 \pm 1.36$ & $5.50 \pm 1.27^{\mathrm{ab}}$ \\
Slow motility (\%) & $31.67 \pm 1.11$ & $29.17 \pm 2.16$ & $33.00 \pm 1.21$ & $6.20 \pm 1.30^{\mathrm{ab}}$ \\
Non motile (\%) & $56.00 \pm 1.77^{\mathrm{b}}$ & $67.83 \pm 2.04^{\mathrm{a}}$ & $64.67 \pm 1.92$ & $30.50 \pm 1.14$ \\
Total motility (\%) & $46.17 \pm 1.62^{\mathrm{b}}$ & $28.17 \pm 1.04^{\mathrm{a}}$ & $31.17 \pm 1.83$ & $62.17 \pm 1.27$ \\
Abnormal sperm (\%) & $36.17 \pm 1.90^{\mathrm{b}}$ & $52.83 \pm 2.34^{\mathrm{a}}$ & $50.67 \pm 2.06$ & $35.33 \pm 2.39$ \\
\hline
\end{tabular}

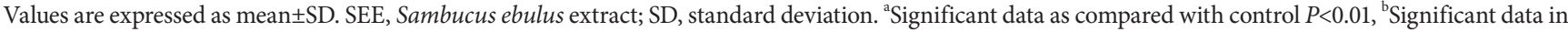
comparison with nicotine $P<0.05$.
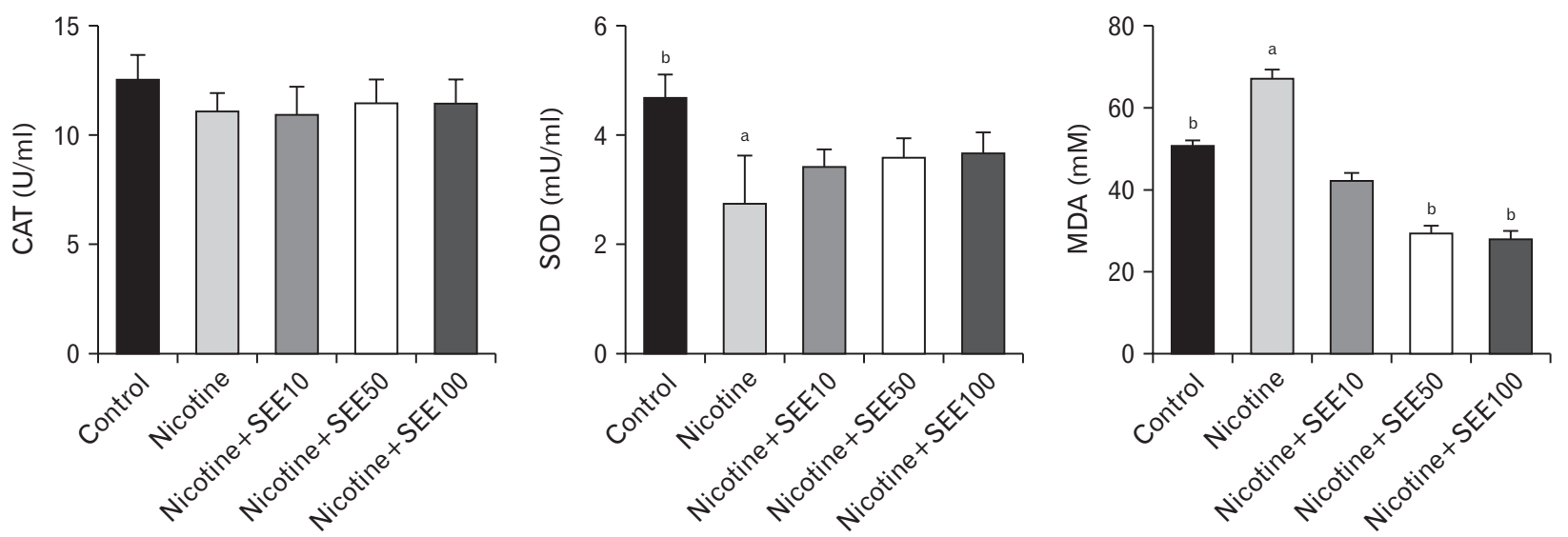

Fig. 3. Serum oxidative stress marker and antioxidant enzymes in different groups treated with nicotine and SEE. ${ }^{2}$ Significant data in comparison with control $P<0.01$. ' Significant data in comparison with nicotine $P<0.01$. Values are expressed as mean. CAT, catalase; MDA, malondialdehyde; SEE, Sambucus ebulus extract; SOD, superoxide dismutase. 
Table 2. The morphometric parameters and Johnson score of the seminiferous tubules in mice treated with nicotine and SEE

\begin{tabular}{lrrrrr}
\hline \multicolumn{1}{c}{ Groups } & \multicolumn{1}{c}{ Control } & Nicotine & Nicotine+SEE $10 \mathrm{mg} / \mathrm{kg}$ & Nicotine+SEE 50 mg/kg & Nicotine+SEE $100 \mathrm{mg} / \mathrm{kg}$ \\
\hline STD $(\mu \mathrm{m})$ & $167.33 \pm 1.35^{\mathrm{b}}$ & $128.33 \pm 2.17^{\mathrm{a}}$ & $127.83 \pm 4.90^{\mathrm{a}}$ & $151.17 \pm 1.22^{\mathrm{ab}}$ & $159.50 \pm 1.75$ \\
GEH $(\mu \mathrm{m})$ & $170.83 \pm 1.49^{\mathrm{b}}$ & $64.50 \pm 1.33^{\mathrm{a}}$ & $70.00 \pm 1.80^{\mathrm{a}}$ & $104.50 \pm 2.56^{\mathrm{ab}}$ & $102.60 \pm 4.44^{\mathrm{ab}}$ \\
Johnson score & $9.83 \pm 0.16^{\mathrm{b}}$ & $7.67 \pm 0.33^{\mathrm{a}}$ & $8.00 \pm 0.51$ & $9.00 \pm 0.44$ & $9.40 \pm 0.24^{\mathrm{b}}$ \\
Leydig cell n/f & $13.96 \pm 0.96$ & $10.33 \pm 0.84$ & $10.83 \pm 0.60$ & $12.33 \pm 1.76$ & $14.25 \pm 0.85$ \\
\hline
\end{tabular}

Values are expressed as mean \pm SD. SEE, Sambucus ebulus extract; SD, standard deviation; STD, seminiferous tubule diameter, GEH, germinal epithelial height, n/f, number/ microscopic field. ${ }^{a}$ Significant data as compared with control $P<0.01$, ${ }^{\text {S}}$ Significant data in comparison with nicotine $P<0.01$.
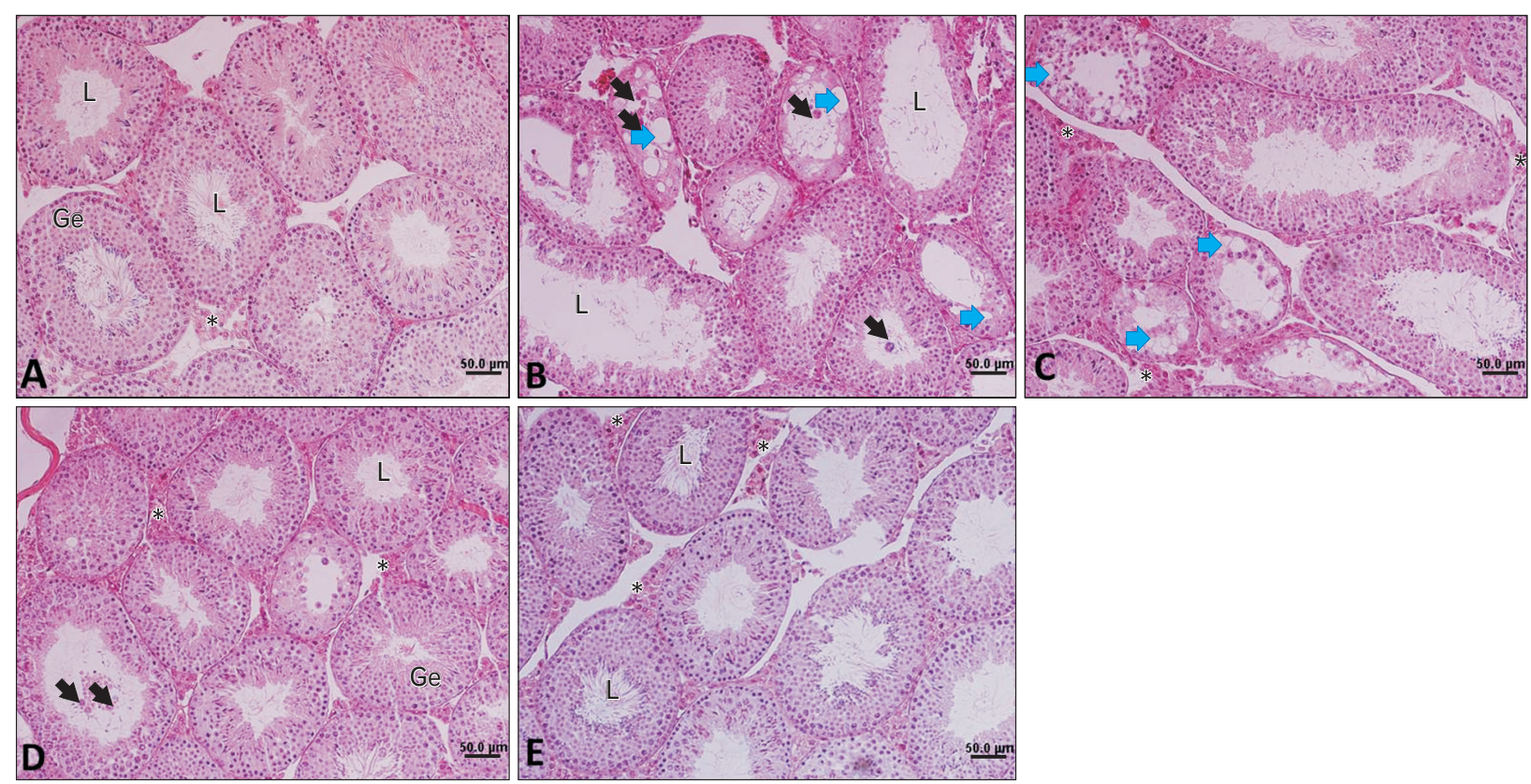

Fig. 4. Testicular photomicrograph. (A) Control group, (B) nicotine, (C) nicotine+SEE $10 \mathrm{mg} / \mathrm{kg}$, (D) nicotine+SEE $50 \mathrm{mg} / \mathrm{kg}$ and (E) nicotine $+100 \mathrm{mg} / \mathrm{kg}$ of SEE. Black arrows show degenerative and sloughed-off cells in the $\mathrm{L}$ of seminiferous tubules. Blue arrows show vacuoles inside seminiferous tubules. Asterisk $\left(^{*}\right)$ shows Leydig cells in the interstitial tissue. (B) The reduction of epithelial height, presence of high vacuoles in the Ge and degenerative cells in the L, and a low score are observed. (D and E) Better organized seminiferous tubules and higher scores are seen $(\mathrm{H} \& \mathrm{E}, \times 200)$. Ge, germinal epithelium; L, lumen; SEE, Sambucus ebulus extract.

the doses of 10, 50 and $100 \mathrm{mg} / \mathrm{kg}$ in the SOD activity. We did not find a significant difference in serum CAT activity between groups (Fig. 3). Treatment with nicotine increased the MDA level, compared with controls $(P<0.01)$. However, co-treatment with nicotine and 50 and $100 \mathrm{mg} / \mathrm{kg}$ of SEE significantly reduced the MDA level, compared with the nicotine-treated group (Fig. 3).

\section{Histopathology of testis}

A normal histological feature of spermatogenesis was observed in the control group. Seminiferous tubules showed a high quality and score (Table 2, Fig. 4). Nicotine induced a low-quality score in seminiferous tubules. It reduced germinal epithelial height and seminiferous tubule diameters. In some tubules, the appearance of vacuoles that would be a sign of germ cell apoptosis was observed. Fragmented degenerative cells were observed in some seminiferous tubules in the nicotine group. However, there was no sign of vacuoles or degenerative cells in the control group (Table 2, Fig. 4). There were no significant statistical differences in the numbers of Leydig cells in microscopic fields between the nicotine and control groups (Table 2). Treatment with SEE ameliorated the adverse effects of nicotine, especially in the doses of 50 and $100 \mathrm{mg} / \mathrm{kg}$. SEE at the doses of 50 and 100 $\mathrm{mg} / \mathrm{kg}$ increased both diameters and height of Ge in seminiferous tubules, compared with the nicotine group $(P<0.01)$. SEE with the doses of $100 \mathrm{mg} / \mathrm{kg}$ increased the Leydig cell numbers, in comparison with the nicotine group. There was no significant statistical difference between the doses of 50 and $100 \mathrm{mg} / \mathrm{kg}$ SEE in diameters and height of Ge in semi- 
niferous tubules (Fig. 4, Table 2). At $10 \mathrm{mg} / \mathrm{kg}$ of SEE, there were vacuoles and degenerative cells in seminiferous tubules. However, these histological signs were few in $50 \mathrm{mg} / \mathrm{kg}$ of SEE and rare in $100 \mathrm{mg} / \mathrm{kg}$ (Fig. 4).

\section{Discussion}

This study showed nicotine has adverse effects on male reproduction through disruption of sex hormone secretion, the elevation of MDA as an oxidative marker and reduction of SOD as an antioxidant marker. Our in vitro findings also showed SEE had no spermicidal effect at different doses of 0 , $5,10,20,50$, and $100 \mathrm{mg}$. SEE ameliorated the adverse effects of nicotine, especially at the doses of 50 and $100 \mathrm{mg} / \mathrm{kg}$. We also showed that 50 and $100 \mathrm{mg} / \mathrm{kg}$ of SEE increased sperm count, sperm motility, and reduced abnormal morphology in nicotine treated animals.

Nicotine is considered as one of the toxic agents in cigarette and has genotoxic effects. It has been shown that nicotine increases testicular and epididymal MDA and NO. However, it reduces testicular SOD levels in rats [6]. SOD has a protective role against oxygen free radicals by catalyzing the deletion of superoxide radicals [6]. It was shown that increased activity of SOD might prevent CAT inactivation by superoxide radicals [31]. Our study showed a lower level of SOD in the nicotine-treated group. Our findings were consistent with a previous study related to nicotine exposure effects on sperm parameters and induced oxidative stress in the testes and prostate [32]. Naturally male reproductive system has two types of antioxidant systems, namely enzymatic and non-enzymatic agents. The enzymatic agents include SOD, CAT, glutathione peroxidase, glutathione reductase, and glutathione-s-transferase [11]. Non-enzymatic agents are vitamins $\mathrm{A}, \mathrm{E}, \mathrm{C}, \mathrm{B}$-complex, melatonin, resveratrol, copper, and selenium [11]. Our findings showed no significant statistical differences in CAT activity between groups. Likely, a previous study showed that nicotine has not affected the CAT activity in rat erythrocytes [33]. Since our study was a preliminary study, so the initial doses of our plant extract were determined from low doses (10 to $100 \mathrm{mg} / \mathrm{kg}$ ). We suggested that the use of higher doses or longer-term treatment of our extract might be more effective than the current treatment method.

Administration of $50,100 \mathrm{mg} / \mathrm{kg}$ of SEE reduced the MDA level, compared with nicotine. The antioxidant activity of SEE has been shown in previous studies $[19,20]$. This property is dependent on the manner of preparation and polarity of the solvent and also the plant part (leaf, fruit, and root) [34]. Researchers have shown that the antioxidant properties of this plant are related to phenolic substances such as caffeic acid and its derivatives and anthocyanin [20, 35]. We analyzed Sambucus ebulus fruits extract and found that its major compounds are $\beta$-sitosterol, oleic acid, ursolic acid, linoleic acid, and caffeic acid based on GC-MS analysis (unpublished data). It has been shown that caffeic acid reduces the level of oxidants and increases the resistance to oxidants in the cell. In other words, it protects the cell against apoptosis caused by oxidative stress [36].

Our findings concerning sperm parameters showed a reduced sperm count, motility, and normal sperms in the nicotine-treated group. The elevation of ROS in smokers leads to abnormality in human semen parameters [32]. Similarly, previous studies also have shown adverse effects of nicotine on animal testicular tissue and epididymal sperm parameters $[5,37]$. The reduced sperm count following nicotine administration may be due to the reduced numbers of the germ cell production in seminiferous tubules, as indicated by our histologic morphometric study. Nicotine reduces the numbers of both primary spermatocytes, round and elongated spermatids [5]. Abnormal sperms may be due to the oxidative stress induced by nicotine as our findings showed a high MDA level in the nicotine-treated group. These alterations led to a reduced quality of spermatogenesis, demonstrated by Johnsen's score. Impairment of reproduction induced by nicotine may also be due to hormonal disturbances. A lower level of testosterone and $\mathrm{LH}$ and also a higher level of prolactin were observed in the nicotine-treated group. Administration of SEE altered the hormonal profiles to a better condition, especially in the doses of 50 and $100 \mathrm{mg} / \mathrm{kg}$. However, LH had an insignificant alteration. Our findings concerning a reduced level of testosterone and $\mathrm{LH}$, suggest that it may be due to the disturbance in the pituitary gland. In this regard, it has been shown that nicotine leads to distortion of the pituitary-gonadal axis and disturbs male reproductive ability $[6,7]$. Testosterone is one of the most important hormones that begins and maintains the spermatogenesis process. It is also necessary for the attachment of germ cells in seminiferous tubules. Therefore, the low level of testosterone may be associated with detachment of germ cells. In this regard, our findings showed a low germinal epithelial height and quality in seminiferous tubules at stages VII and VIII in the nicotine-treated group. Our findings were similar to the previous 
studies about the effects of nicotine on spermatogenesis [8, $17,38]$. Testosterone is produced by Leydig cells in testicular interstitial tissue under the action of LH. Probably, reduced $\mathrm{LH}$ has been caused to reduce the activity of Leydig cells. In this regard, it has been shown that nicotine alters enzymes involved in steroidogenesis. Nicotine inhibits both transcription and translation of testicular StAR, as a key regulatory protein for the synthesis of testosterone in Leydig cells [8].

Our study showed a hike in prolactin following treatment with nicotine. Prolactin receptors are found on spermatogonia and spermatocytes in seminiferous tubules. It means that prolactin has a role in a normal spermatogenesis process [39]. Hyperprolactinemia in men resulted in abnormal semen parameters, decreased libido, and erectile dysfunction [7]. It also may reduce the production of FSH and LH and impact on the production of testosterone in Leydig cells, and therefore, impairs male reproduction and male fertility [7]. An increase of spermatogenesis activity and modification in hormones and epididymal sperm parameters in SEE-treated groups may be due to lower production of ROS caused by nicotine and, our findings support that.

In conclusion, this study indicated beneficial effects of SEE in the doses of 50 and $100 \mathrm{mg} / \mathrm{kg}$ on male reproduction impairment induced by nicotine, which might be partly attributed to the reduction of oxidative stress and changes in the hormones of the pituitary-gonadal axis.

\section{ORCID}

Fahimeh Mohammadghasemi:

https://orcid.org/0000-0002-7627-9787

Korosh Khanaki: https://orcid.org/0000-0003-0733-6933

Hamid Moravati: https://orcid.org/0000-0002-3916-3611

Masoumeh Faghani:

https://orcid.org/0000-0001-6011-1958

\section{Author Contributions}

Conceptualization: FMGH, MF. Data acquisition: MF, $\mathrm{KKH}, \mathrm{HM}$, Data analysis or interpretation: FMGH, MF. Drafting of the manuscript: FMGH, MF. Critical revision of the manuscript: FMGH, MF. Approval of the final version of the manuscript: all authors.

\section{Conflicts of Interest}

No potential conflict of interest relevant to this article was reported.

\section{Acknowledgements}

This study was financially supported by the Deputy of Research and Technology, Gulian University of Medical Sciences (IR.GUMS.REC.1396. 349).

\section{References}

1. Mishra A, Chaturvedi P, Datta S, Sinukumar S, Joshi P, Garg A. Harmful effects of nicotine. Indian J Med Paediatr Oncol 2015;36:24-31.

2. Chu KM, Cho CH, Shin VY. Nicotine and gastrointestinal disorders: its role in ulceration and cancer development. Curr Pharm Des 2013;19:5-10.

3. Mello PR, Pinto GR, Botelho C. [The influence of smoking on fertility, pregnancy and lactation]. J Pediatr (Rio J) 2001;77:25764. Portuguese.

4. Saadat SN, Mohammadghasemi F, Jahromi SK, Homafar MA, Haghiri M. Melatonin protects uterus and oviduct exposed to nicotine in mice. Interdiscip Toxicol 2014;7:41-6.

5. Mohammadghasemi F, Jahromi SK. Melatonin ameliorates testicular damages induced by nicotine in mice. Iran J Basic Med Sci 2018;21:639-44.

6. Oyeyipo IP, Raji Y, Bolarinwa AF. Antioxidant profile changes in reproductive tissues of rats treated with nicotine. J Hum Reprod Sci 2014;7:41-6.

7. Oyeyipo IP, Raji Y, Bolarinwa AF. Nicotine alters male reproductive hormones in male albino rats: the role of cessation. J Hum Reprod Sci 2013;6:40-4.

8. Jana K, Samanta PK, De DK. Nicotine diminishes testicular gametogenesis, steroidogenesis, and steroidogenic acute regulatory protein expression in adult albino rats: possible influence on pituitary gonadotropins and alteration of testicular antioxidant status. Toxicol Sci 2010;116:647-59.

9. Mohammadghasemi F, Jahromi SK, Hajizadeh H, Homafar MA, Saadat N. The protective effects of exogenous melatonin on nicotine-induced changes in mouse ovarian follicles. J Reprod Infertil 2012;13:143-50.

10. Guo X, Wang H, Wu X, Chen X, Chen Y, Guo J, Li X, Lian Q, Ge RS. Nicotine affects rat Leydig cell function in vivo and vitro via down-regulating some key steroidogenic enzyme expressions. Food Chem Toxicol 2017;110:13-24.

11. Mohammadghasemi F. Melatonin, antioxidant capacity, and male reproductive function. In: Preedy VR, editor. Pathology. London: Elsevier; 2020. p.265-75.

12. Dai JB, Wang ZX, Qiao ZD. The hazardous effects of tobacco 
smoking on male fertility. Asian J Androl 2015;17:954-60.

13. Koskinen LO, Collin O, Bergh A. Cigarette smoke and hypoxia induce acute changes in the testicular and cerebral microcirculation. Ups J Med Sci 2000;105:215-26.

14. Turner TT, Lysiak JJ. Oxidative stress: a common factor in testicular dysfunction. J Androl 2008;29:488-98.

15. Agarwal A, Leisegang K, Sengupta P. Oxidative stress in pathologies of male reproductive disorders. In: Preedy VR, editor. Pathology. London: Elsevier; 2020. p.15-27.

16. Dai J, Zhan C, Xu W, Wang Z, Nie D, Zhao X, Zhang D, Gu Y, Wang L, Chen Z, Qiao Z. Nicotine elevates sperm motility and induces Pfn1 promoter hypomethylation in mouse testis. Andrology 2015;3:967-78.

17. Aydos K, Güven MC, Can B, Ergün A. Nicotine toxicity to the ultrastructure of the testis in rats. BJU Int 2001;88:622-6.

18. Condorelli RA, La Vignera S, Giacone F, Iacoviello L, Vicari E, Mongioi L, Calogero AE. In vitro effects of nicotine on sperm motility and bio-functional flow cytometry sperm parameters. Int J Immunopathol Pharmacol 2013;26:739-46.

19. Cvetanović A. Sambucus ebulus L., antioxidants and potential in disease. In: Preedy VR, editor. Pathology. London: Elsevier; 2020. p.321-33.

20. Ebrahimzadeh MA, Ehsanifar S, Eslami B. Sambucus ebulus elburensis fruits: a good source for antioxidants. Phcog Mag 2009;5:213-8.

21. Shokrzadeh M, Saeedi Saravi SS, Mirzayi M. Cytotoxic effects of ethyl acetate extract of Sambucus ebulus compared with etoposide on normal and cancer cell lines. Phcog Mag 2009;5:3169.

22. Ivanova D, Tasinov O, Kiselova-Kaneva Y. Improved lipid profile and increased serum antioxidant capacity in healthy volunteers after Sambucus ebulus L. fruit infusion consumption. Int J Food Sci Nutr 2014;65:740-4.

23. Jabbari M, Hashempur MH, Razavi SZ, Shahraki HR, Kamalinejad M, Emtiazy M. Efficacy and short-term safety of topical dwarf elder (Sambucus ebulus L.) versus diclofenac for knee osteoarthritis: a randomized, double-blind, active-controlled trial. J Ethnopharmacol 2016;188:80-6.

24. Karami M, Ale-Nabi SS, Nosrati A, Naimifar A. The protective effect of Sambucus ebulus against lung toxicity induced by gamma irradiation in mice. Pharm Biomed Res 2015;1:48-54.

25. Khillare B, Shrivastav TG. Spermicidal activity of Azadirachta indica (neem) leaf extract. Contraception 2003;68:225-9.

26. Souad K, Ali S, Mounir A, Mounir TM. Spermicidal activity of extract from Cestrum parqui. Contraception 2007;75:152-6.

27. Nie D, Zhang D, Dai J, Zhang M, Zhao X, Xu W, Chen Z, Wang L, Wang Z, Qiao Z. Nicotine induced murine spermatozoa apoptosis via up-regulation of deubiquitinated RIP1 by Trim27 promoter hypomethylation. Biol Reprod 2016;94:31.

28. Emami NH, Lafout FM, Mohammadghasemi F. Administration of melatonin protects against acetylsalicylic acid-induced impairment of male reproductive function in mice. Iran J Basic Med Sci 2018;21:124-9.

29. Aral F, Karaçal F, Baba F. The effect of enrofloxacin on sperm quality in male mice. Res Vet Sci 2008;84:95-9.

30. Kohestani Y, Kohestani B, Shirmohamadi Z, Faghani M. Effect of tamsulosin on testis histopathology and serum hormones in adult rats: Experimental study. Int J Reprod Biomed 2020;18:531-8.

31. Blum J, Fridovich I. Inactivation of glutathione peroxidase by superoxide radical. Arch Biochem Biophys 1985;240:500-8.

32. Budin SB, Kho JH, Lee JH, Ramalingam A, Jubaidi FF, Latif ES, Zainalabidin S, Taib IS, Mohamed J. Low-dose nicotine exposure induced the oxidative damage of reproductive organs and altered the sperm characteristics of adolescent male rats. Malays J Med Sci 2017;24:50-7.

33. Suleyman H, Gumustekin K, Taysi S, Keles S, Oztasan N, Aktas O, Altinkaynak K, Timur H, Akcay F, Akar S, Dane S, Gul M. Beneficial effects of Hippophae rhamnoides L. on nicotine induced oxidative stress in rat blood compared with vitamin $\mathrm{E}$. Biol Pharm Bull 2002;25:1133-6.

34. Topuzović MD, Stanković MS, Jakovljević DZ, Bojović BM. Plant part variability of Sambucus ebulus L. Secondary metabolites content and antioxidant activity. Agro Food Ind Hi Tech 2016;27:60-3.

35. Shokrzadeh M, Saeedi Saravi SS. The chemistry, pharmacology and clinical properties of Sambucus ebulus: a review. J Med Plants Res 2010;4:95-103.

36. Wan T, Wang Z, Luo Y, Zhang Y, He W, Mei Y, Xue J, Li M, Pan H, Li W, Wang Q, Huang Y. FA-97, a new synthetic caffeic acid phenethyl ester derivative, protects against oxidative stressmediated neuronal cell apoptosis and scopolamine-induced cognitive impairment by activating $\mathrm{Nrf} 2 / \mathrm{HO}-1$ signaling. Oxid Med Cell Longev 2019;2019:8239642.

37. Reddy S, Londonkar R, Ravindra, Reddy S, Patil SB. Testicular changes due to graded doses of nicotine in albino mice. Indian J Physiol Pharmacol 1998;42:276-80.

38. Seema P, Swathy SS, Indira M. Protective effect of selenium on nicotine-induced testicular toxicity in rats. Biol Trace Elem Res 2007;120:212-8.

39. Hondo E, Kurohmaru M, Sakai S, Ogawa K, Hayashi Y. Prolactin receptor expression in rat spermatogenic cells. Biol Reprod 1995;52:1284-90. 